\title{
UNA SEMBLANZA DE LA PROFESORA PALOMA GARCIA PICAZO
}

\author{
Antonio Marquina ${ }^{1}$ \\ Instituto Universitario "General Gutiérrez Mellado"/ UNISCI
}

\section{Resumen:}

La profesora Paloma García Picazo, fallecida en Madrid el 11 de Agosto de 2018, ha dejado una impronta significativa en el campo de las relaciones internacionales en España. Su amplia obra científica, diversificada en diez líneas de investigación, y su dedicación en la docencia constituyen un ejemplo de resposabilidad y dedicación universitaria.

Palabras Clave: Investigación, docencia, relaciones internacionales. España

Títle in English: Professor Paloma García Picazo: A biographical sketch

\begin{abstract}
:
Professor Paloma García Picazo died in Madrid on August 11, 2018. She has left a significant imprint in the field of international relations in Spain. His extensive scientific work, diversified into ten lines of research and his dedication and commitment in the teaching activities are an example of responsibility and university dedication.
\end{abstract}

Key Words: Research, teaching activities, international relations, Spain

Copyright @ UNISCI, 2019.

Las opiniones expresadas en estos artículos son propias de sus autores, y no reflejan necesariamente la opinión de UNISCI. The views expressed in these articles are those of the authors, and do not necessarily reflect the views of UNISCI

\footnotetext{
${ }^{1}$ Antonio Marquina Barrio es Catedrático de Seguridad y Cooperación Internacional (emérito) y Director de UNISCI (www.unisci.es). Profesor del Insituto Universitario "General Gutiérrez Mellado".

E-mail: <amarqbar45@gmail.com>

DOI: http://dx.doi.org/10.31439/UNISCI-55
} 


\section{Introducción}

La profesora Paloma García Picazo, Profesora titular de relaciones internacionales de la Universidad Nacional de Educación a Distancia (UNED), Vicedecana de Ordenación Académica y Profesorado y profesora del Instituto Universitario General Gutiérrez Mellado desde al año 2010 hasta el año 2018 ha sido una profesora que ha dejado un rastro académico indiscutible en el ámbito académico de las relaciones internacionales.

Nació en Madrid el 6 de mayo de 1953 y falleció el 11 de agosto de 2018, dejando una significativa obra científica, muy personal, sobre diversas cuestiones de relaciones internacionales

Su formación en el Colegio Alemán de Madrid dejará en ella una impronta especial de conocimiento de pensadores y clásicos que se verá reflejado en su obra. Posteriormente realizará la licenciatura en la Facultad de Ciencias Políticas y Sociología de la Universidad Complutense de Madrid y más tarde en 1992 defendió su tesis doctoral titulada "Mente y mundo:Aproximación sistémica a las Relaciones Internacionales desde la Cultura", dirigida por el catedrático de relaciones internacionales, Roberto Mesa, una tesis voluminosa de unas mil páginas, considerada una tesis ambiciosa con una aproximación personal y también global a la disciplina de relaciones internacionales ${ }^{2}$.

En 1993 entró a formar parte del claustro de profesores de la UNED como profesor ayudante y en 1997 llegó a ser profesor titular, realizando una notable actuación en el campo docente e investigador. Aunque no realizó destacadas estancias en universidades extranjeras o participó en multiples congresos o seminarios internacionales, sí mantuvo contactos con profesores de otras universidades europeas.

\section{Actividad docente e investigadora}

Su amplia obra presenta distintos apartados. Paloma, en su memoria del curso 2009-2010 sobre la Idea de Europa, mencionará que tenía nueve líneas de investigación.

De todas ellas, en primer término, hay que destacar sus estudios y manuales sobre relaciones internacionales en un sentido general, empezando en 1994 con el manual sobre "Organización Política y Administrativa Intrernacional" publicado de forma conjunta con el profesor Gustavo Palomares, seguido en 1995 con otro manual en colaboración con este mismo profesor sobre "Relaciones Internacionales: Sociedad Internacional" que alcanzará varias ediciones. Tres años más tarde, en 1998 hará su primera incursión independiente con el libro" Las Relaciones Internacionales en el siglo XX: La contienda teórica" libro publicado en la UNED y que será utilizado por los alumnos como libro de texto alcanzando varias reimpresiones, al que seguirán, en orden cronológico, su obra "Teoría breve de Relaciones Internacionales. ¿Una anatomía del mundo?” publicada en 2004, revisada en 2013 y que alcanzó su quinta edición en 2017; el libro "¿Qué es esa cosa llamada 'Relaciones Internacionales'? Tres lecciones de autodeterminación y algunas consideraciones deterministas", publicado en 2010; en este mismo año también el libro "El sistema mundial: perspectivas políticas y sociológicas"; y dos años después, en 2012, "La investigación del medio internacional. Fundamentos teóricos y conceptuales, métodos y técnicas". Esta temática sobre sociedad internacional, globalización, desorden internacional, los Balcanes, la reconfiguración de Oriente Próximo tras la Primera Guerra Mundial, o la metodología de relaciones internacionales será retomada en diveros artículos o capítulos de libros en colaboración en 2002, 2003, 2004, 2005 y 2015, e incluso se adentrará poco antes de su fallecimiento, en 2018, en el análisis de Hamlet y Segismundo, como emblemas políticos del

\footnotetext{
2 Véase Barbé Izuel Esther:” In Memoriam, Paloma García Picazo”, Biblioteca de Ciencia Jurídica, Barcelona 14
} de diciembre de 2018 
sistema de Estados europeo del siglo XVII y arquetipos de dramas barrocos desde la teoría de las relaciones internacionales, en un artículo en la Revista Studia Historica.

Otra línea de investigación está centrada en la cultura y civilización en el contexto internacional que dimanará de su tesis doctoral, considerada "uno de los elementos estructurales básicos sobre los que se asienta la vida internacional en su origen y evolución". ${ }^{3}$ Así titulará su libro sobre la idea europea de 2008: "La idea de Europa. Historia, Cultura, Política".

En este tema, podemos encontrar diversas aportaciones en revistas y capítulos de libros, empezando en 1993 con el artículo "Totalidad y fragmentación. El mundo de la cultura, el universo de la civilización" en la Revista Española de Investigaciones Sociológicas; en 1994 hará una disección sobre uno de sus temas favoritos, el tema europeo, diseccionando "La Europa de la cultura y las culturas de Europa" en la revista de Occidente; en 1999, con el capítulo "El diálogo cultural vs dialéctica política: La dimensión intercultural en el pensamiento internacional del Mediterráneo. Tres enfoques teóricos"; dos años después con su aportación a los Papeles y Memorias Tribuna Joven de la Academia de Ciencias Morales y Políticas sobre "Las relaciones internacionales y la cultura"; en 2003 entrando a debatir otro tema de su interés, el tema religioso, con un estudio sobre "Religión y cultura en la configuración de la sociedad internacional"; en el libro homenaje al catedrático José Giménez y Martínez de Carvajal, uno de los profesores que citará en varias de sus obras; en 2005, con su capítulo sobre "El presente distante. Fundamentalismos y multiculturalidad en un mundo globalizado" o su conferencia en el centro cultural Blanquerna, posteriormente publicada, titulada, "Humanidad y humanidades hoy: ¿con rumbo o a la deriva?” donde consideró que la situación de la cultura era lamentable, señalando que "frente al relato uniforme y mítico de la Modernidad, constituido como discurso único y excluyente, se abre el sistema abierto de las culturas y civilizaciones repartidas por toda la Tierra, patrimonio universal del ser humano como especie en evolución"; y en el epílogo destacará unos párrafos que reproducimos: "La humanidad es un concepto frío, abstracto, lejano, con el que es difícil identificarse. Nadie "ama" realmente a la humanidad, aunque el corazón tiene razones que la razón no entiende, como decía Pascal. Pero lo corriente es que se ame aquello que se conoce. En clave identitaria, lo que se conoce, por afinidad y cercanía, es lo que podemos llamar las «patrias» (Heimatland, Vaterland), que ¿por qué no empezamos a pensarlas como «matrias» o como «fratrias»? Hannah Arendt, desde no ya el exilio, sino desde los exilios múltiples que tuvo que padecer a lo largo de su vida, consideraba que su patria era su lengua materna, su Muttersprache. Para mí también las "patrias" son las lenguas. Son, creo, las mejores "patrias", las únicas con valor de supervivencia, pues encaman el logos, el universo cognitivo y afectivo del Verbo".

Otra de sus líneas de investigación será el hecho religioso en el contexto internacional, que impreganará buena parte de sus publicaciones. De forma especial merecen destacarse, entre otros, su primera aportación en 1993 en un artículo de la revista católica internacional Communio en colaboración con el catedrático Carlos Corral S.J., titulado "La arquitectura para la nueva Europa, la perspectiva eclesial" y también en colaboración con este catedrático, el capítulo "Iglesia y Europa: sus respectivas relaciones como comunidades" en el libro "La construcción de la Casa Común Europea"; en 1994 el capítulo titulado "Panorámica de los fundamentalismos religiosos, hoy, en las relaciones internacionales" en el libro "Los Fundamentalismos religiosos hoy"; el capítulo ya citado sobre "Religión y cultura en la configuración de la sociedad internacional", en el libro homenaje al catedrático José Giménez y Martínez de Carvajal, publicado en 2003; el libro de 2008 titulado "Política e identidad cristiana en los 'padres fundadores' de la Unión Europea”; y el interesante artículo de 2010

\footnotetext{
${ }^{3}$ García Picazo Paloma (2010): ¿Qué es esa cosa llamada `Relaciones Internacionales”?, Madrid, Marcila Pons, p.181.
} 
publicado en la Revista Española de Derecho Internacional, titulado "Perspectivas sobre el hecho religioso en el sistema mundial contemporáneo". Para el año siguiente hacer en la reunión de la Asociación española de profesores de derecho internacional y relaciones internacionales una exposición titulada "Dialéctica de la secularización: una fenomenología de los conflictos en la sociedad internacional" donde se pregunta, como hipótesis central, "si la secularización es per se una clave de pacificación -argumento convencional desde la Paz de Westfalia- o si consiste en la mera transformación de unos pretextos conflictivos, presentados como religiosos en una situación dada, en otros ideológicos, cuando en realidad lo que se persigue de forma encubierta son intereses de índole política, social, económica, cultural, étnica, identititaria", preguntándose si la religión, en sí misma y en cualquiera de sus manifestaciones, era un factor polémico o irénico, concluyendo, tras citar las posiciones de diversos autores, que la secularidad no era sólo un problema relativo a la religión, ni tampoco una institución política, sino algo relacionado "con el hecho de habitar un mundo común sin absolutos universalmente compartidos ni nociones que transciendan la mundanidad, válidas para todos". La solución a los conflictos dentro de la dialéctica de la secularización en la sociedad internacional era entonces posible, siendo necesario que "la inteligencia y el derecho prevalecieran sobre la idiotez y la fuerza".

Pero será, sin duda, el tema europeo, tras sus estudios y manuales sobre relaciones internacionales en general, la línea investigadora de segunda mayor importancia en su actividad académica e investigadora. En este tema, la autora se dice deudora de los catedráticos Antonio Truyol, Carlos Corral y Manuel Díez de Velasco. Aparte de los libros ya citados: "La idea de Europa: Historia, Cultura, Política" y "Política e identidad cristiana en los 'padres fundadores' de la Unión Europea”, podemos encontrar una producción amplia de artículos y capítulos de libros. Según hemos podido recoger, sin ánimo de ser exhaustivos: Once capítulos de libros y dieciséis artículos en diversas revistas: Claves de la Razón Práctica, Tiempo de Paz, Revista de Occidente, Política y Sociedad, Patrimonio Cultural, Ars Sacra, Boletín de la Real Academia de la Historia. A lo que se unirá el seguimiento y algunas publicaciones sobre la realidad política y social de Alemania que ella también considerará como una línea propia e independiente de su investigación. Paloma era profundamente europeísta, con un europeísmo, como ella dirá, no subvencionado.

Una cuarta línea investigadora lo consituirá el estudio de los nacionalismos en el contexto internacional, habiendo participado como coordinadora de la edición de la Enciclopedia del nacionalismo dirigida por el catedrático Andrés de Blas con la elaboración de 21 voces o asuntos temáticos.

También seguirá los temas africanos y tendrá una buena relación con el CIDAF (Centro de Información y Documentación Africanas) que tiene su sede en la calle Gaztambide en Madrid y que dirigen los Padres Blancos, aunque su producción en este campo sea escasa, si bien ella lo conisderó otra de sus líneas de investigación.

Más tardíamente prestará atención a la teoría de género y las relaciones internacionales, publicando, a partir de 2009, diversos estudios en libros colectivos sobre la violencia de género y la violencia contra las mujeres desde diversas perspectivas: la filosofía, la psiquitría, la sociología, la perspectiva europea, siendo la última aportación, realizada en 2016 y titulada "Violencia de género: ¿qué "género" de violencia? Tristes tòpicos: esas cosas que son ‘como son’ ¿cómo son en realidad?”, en el libro colectivo coordinado por Teresa San Segundo: "A vueltas con la violencia. Una aproximación multidisciplinar de la violencia de género", la más significativa a mi juicio. A ello se une la dirección reciente, antes de su fallecimiento, de un trabajo fin de Master en el Instituto Universitario, "General Gutiérrez Mellado", titulado "La relevancia de la mujer guerrera en la Edad Media: algunas perspectivas desde el pensamiento coetáneo y ejemplos del desempeño femenino en la acción bélica”. Paloma era feminista y era 
crítica con la situación de la mujer, como se puede comprobar en el epílogo de su libro "Teoría breve de Relaciones Internacionales". Pero, frente a otros planteamientos, no pensaba como mujer sino como "una persona y un ser que piensa".

Dentro de su amplio espectro investigador y cultural hay que citar también sus publicaciones sobre el patrimonio artístico y cultural con numerosos artículos en las revistas Patrimonio Cultural y Ars Sacra que se inician en 1995.

Pero será su paso por el Instituto Universitario “General Gutiérrez Mellado” lo que hará que desarrolle una investigación propia y profunda sobre el tema de la guerra. Con anterioridad, en 2005 había publicado en la Revista Internacional de Fiosofía Política, de la que era miembro del Consejo de Redacción, un diálogo donde abordaba la dimensión teórica del debate sobre la seguridad, realizado con los profesores Esther Barbé y Rafael Gacía Pérez que llevaba por título "Las relaciones internacionales hoy. ¿Quién diría que éste es un mundo más seguro?". Y en este mismo año publicó otro artículo ligando el tema de la guerra y la paz con uno de sus temas favoritos, el proceso de civilización. El artículo se titula "De la guerra perenne a una paz precaria: Las relaciones internacionales y el proceso de civilización", donde considera que la guerra ha llegado a ser un insulto a la inteligencia y la encarnación de lo peor, un grave problema moral, "causa y consecuencia de todos los problemas de la humanidad". Al año siguiente, en la revista Tiempo de Paz hará una disquisición sobre la Alianza de civilizaciones, preguntándose sobre si constituía una tentativa de pacificación mundial. Años más tarde, en 2011, con motivo de la jornada anual de la Asociación española de profesores de derecho internacional y relaciones internacionales, Paloma hará una disertación sobre "Dialéctica de la secularización: una fenomenología de los conflictos en la sociedad internacional" que ya hemos mencionado.

El libro que recoge su pensamiento sobre la guerra aparecerá en 2016 con el título "La Guerra y la Paz en teoría" con el subtítulo "Un recorrido por la historia y el pensamiento de los clásicos internacionales". Un libro denso, que dice inspirarse en Martin Wight y que "propone un conjunto de lecturas hilvanadas que intentan poner en claro... algunos de los conceptos, autores, obras, temas y circunstancias que, en términos teóricos se relacionan con la guerra y con la paz dentro de los parámetros de la cultura occidental". Aunque la autora señala que todo lo sustativo sobre el tema ya se ha dicho y que pocos son los vivos capaces de aportar alguna idea que supere a unos clásicos milenarios, la realidad es que Paloma podría, si hubiera tenido más años de vida, adentrarse en las otras formas de hacer la guerra que se abren con la utilización de las armas nucleares y que llegan a nuestros días con las ciberguerras y su contextualización. Este libro, aunque cite a Johan Galtung o Samuel Huntington, no se adentra en la importante producción filosófica sobre la guerra que induce el tema nuclear. Curiosamente en su libro “Teoría breve de Relaciones Internacionales. ¿Una anatomía del mundo?” citado, incide en algunas cuestiones y autores que podría haber también aprovechado en este otro libro y que creo que, como ya dije, si hubiera tenido más años de vida, habría intentado abordar en otra monografía. Aunque era una "pacifista" que consideraba la guerra como lo "peor", también reconocía que los temas de seguridad no pueden reducirse a la guerra y tenían su propia gramática que había que conocer en profundidad, reconocimiento, a la postre, que la distanciaba de otros profesores de relaciones internacionales que se adentraban en esta materia con planteamientos superficiales o heterogéneos.

Aparte de toda esta producción sobre cuestiones internacionales, podemos citar que Paloma también escribió artículos sobre migraciones, terrorismo, cambio climático, China, sobre Esteban de Arteaga y, seguramente, algún tema más que se me escapa. A lo que hay que añadir su labor de traducción de dos obras importantes publicadas por la editorial Tecnos, la "Historia del derecho internacional público" de Antonio Truyol y el libro de John Markoff "Olas de democracia: Movimientos sociales y Cambio político". 
A lo que, además, hay que añadir otra faceta, la narrativa, que aparece en su libro "El Pasaje de las Ánimas", publicado por la editorial SIAL en 2010, donde la autora se pregunta si somos dueños de nuestra vida o responde ésta al capricho del azar. O su prólogo al libro del poeta José Alcalá-Zamora titulado "Armadoc", un prólogo fuerte y duro.

$\mathrm{Si}$ a todo esto se añaden sus conferencias, videos o las tesis doctorales dirigidas, podemos decir que es una lástima que Paloma no haya llegado a ser catedrática de relaciones internacionales. El sistema universitario español, sin adentranos en banderías y su fuerte impregnación de políticos partidarios cuyo ascenso viene predeterminado, falla en este campo de forma estrepitosa. Este es un ejemplo bastante atronador. Sobre todo, si se hacen comparaciones, que siempre son odiosas.

Paloma citará en sus obras a sus principales maestros y es curioso que nombre de forma prominente a un catedrático de sociología, Jesús Ibáñez, a quien citó largamente en varias de sus obras y le consideró una de las personas más inteligentes de su generación en España. Al catedrático Antonio Truyol con el que compartió ideas, anécdotas, comentarios y visión de los clásicos. Al catedrático Carlos Corral con quien dice se inició en la docencia específica sobre Europa y compartió publicaciones e intereses comunes. Al catedrático Manuel Diez de Velasco, quien una vez jubilado y emérito acabó matriculándose en la UNED en la Facultad de Ciencias Políticas y Sociología, con quien mantuvo una estrecha relación y de quien hará una elogiosa semblanza en su libro sobre La idea de Europa. Sin embargo, citará en pocas ocasiones a su director de tesis, Roberto Mesa, con quien mantuvo una gran amistad. También citará a sus compañeros de la UNED y a otros catedráticos y profesores más de pasada. A sus hijos y amigos. Al director de la editorial Tecnos, Manuel González Moreno, donde publicó buena parte de sus libros. Y, sobre todo, hablará de sus alumnos, del oficio de enseñar, la responsabilidad, la exigencia del profesor. Tratará en sus libros de "trasladar a un lenguaje relativamente sencillo cosas que son complejas, lejanas e inaccesibles". En este sentido cabe destacar el libro "La investigación del medio internacional" donde trata de facilitar la investigación, el desarrollo de la investigación y las técnicas de investigación. Y presentará con gran sensatez los objetivos de sus libros, a veces con gran desenfado ("la autora de este libro no es nadie"; "este libro está pensado y ha sido escrito para personas que se preguntan cosas"; "este libro está lleno de defectos"; "esta obra no es ni un 'libro de texto' ni una `manual'...No obstante, este libro sirve para enseñar y aprender"; "Esta autora confía en transmitir un itinerario practicable por un camino que ella recorre poco a poco, sin otra cosa que la convicción de su ignorancia") que, en la mayoría de los casos, no son manuales al uso sobre asignaturas determinadas y ella misma lo reconoce. En ocasiones resultan complejos y brillantes, con una erudición fuera de lo común, con una cita amplia de autores antiguos y modernos, de "los clásicos" y de detalles históricos o culturales que impresionan al lector y dan un colorido especial a su explicación. Paloma tenía una sólida formación humanística.

En general, podemos decir que Paloma era una profesora vitalista, con un idealismo racional, en "busca de la felicidad", en un "mundo que no es fácil de entender", "su rumbo y su deriva", con una perspectiva religiosa de la vida. Una gran persona y una gran profesora. 